NISTIR 7742

\title{
Customized Common Industry Format Template for Electronic Health Record Usability Testing
}

\author{
Robert M. Schumacher \\ User Centric. Inc, \\ Svetlana Z. Lowry \\ Information Access Division \\ Information Technology Laboratory \\ National Institute of Standards and Technology
}


NISTIR 7742

\section{Customized Common Industry Format Template for Electronic Health Record Usability Testing}

Robert M. Schumacher User Centric. Inc,

Svetlana Z. Lowry Information Access Division Information Technology Laboratory National Institute of Standards and Technology

November 2010

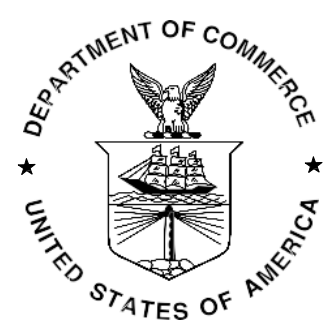

U.S. Department of Commerce Gary Locke, Secretary

National Institute of Standards and Technology Patrick D. Gallagher, Director 


\section{Customized Common Industry Format Template for Electronic Health Record Usability Testing}

\section{INTENDED AUDIENCE}

This document provides a template for the modified version of Software engineering Software product Quality Requirements and Evaluation(SQuaRE) - Common Industry Format (CIF) for usability test reports (ISO/IEC 25062:2006(E)), the Common Industry Format (CIF) usability test report. This version of the CIF has been customized for use in usability testing of Electronic Health Records (EHRs) by usability administrator(s) and data logger(s). The template enables usability engineers to effectively communicate the results of EHR usability testing.

\section{INTENDED PURPOSE}

The intention of the CIF is to help vendors demonstrate evidence of usability in their final product in a format that allows both independent evaluation of a single product and comparison across multiple products. This document has been prepared as a template to guide EHR usability test administrators meet the usability processes approach put forth by the National Institute of Standards and Technology (NIST). The following customized CIF template is intended to assist EHR vendors, healthcare providers, and researchers in reporting the results of usability testing for each system tested.

\section{USING THIS DOCUMENT}

This document is not intended to be a tutorial on usability or usability testing. ${ }^{1}$ To work with this document you should have expertise with common usability industry practices

\footnotetext{
${ }^{1}$ Excellent starting points for information are www.usability.gov and www.upassoc.org as well as Dumas, J., Redish, J. (1994) A Practical Guide to Usability Testing. Norwood, NJ: Ablex. Dana Chisnell \& Jeffrey Rubin Handbook of Usability Testing: How to Plan, Design, and Conduct
} 
and with standard ISO/IEC 25062:2006. ${ }^{2}$ The ISO document is intended for the reporting of summative (i.e., quantitative) studies. The modifications here allow for the reporting of qualitative findings (i.e., formative) but strongly recommend and encourage the collection of quantitative measures of user performance.

Reports delivered using this template should conform to the major headings and content areas outlined below. Minor deviations from the outline and format are acceptable, but the reports should follow the template in all material aspects. This template includes the following sections: ${ }^{3}$

- Executive Summary

- Introduction

- Method

- Results

- Appendices

In addition to these sections, the modified CIF must also include a title page; a sample title page is included in the template example.

When completing the modified CIF template, it is highly recommended that EHR usability test administrator(s) and their data logger(s) refer to the instructions and guidance in order to properly complete this template.

The sample data provided in this template is an example or placeholder of the types of content that may be useful in completing the modified CIF template. Gray background text (bounded in square brackets) needs to be replaced by the EHRs' supplied information. It is important to note that this sample content is not to be taken literally or as a starting point.

Effective Tests (2nd ed.) Wiley, 2008.

Schumacher (2009). Handbook of Global User Research. Burlington, MA: Morgan Kaufman.

2 This document can be purchased from:

http://www.iso.org/iso/iso catalogue/catalogue tc/catalogue detail.htm?csnumber=43046.

${ }^{3}$ Each of these sections has a corresponding section in the ISO/IEC 25062. 


\section{EHR Usability Test Report of [Name of Product and Version Tested]}

Report based on ISO/IEC 25062:2006 Common Industry Format for Usability Test Reports

[Full Name of Product and Version Tested]

Date of Usability Test:

Date of Report:

Report Prepared By:
[Date Usability Test Was Conducted]

[Date Report Was Prepared]

[Name of System Test Laboratory (STL)]

[STL Contact Person, Title and Affiliation]

[STL Phone Number]

[STL Email Address]

[STL Mailing Address]

\section{Table of Contents}

1 EXECUTIVE SUMMARY

2 INTRODUCTION 10

3 METHOD 10

$\begin{array}{lll}3.1 & \text { PARTICIPANTS } & 10\end{array}$

3.2 STUDY DESIGN 11

3.3 TASKS 12

3.4 PROCEDURE 13

3.5 TEST LOCATION

$\begin{array}{ll}3.6 & \text { TEST ENVIRONMENT } \\ 3.7 & 15\end{array}$

3.7 TEST FORMS AND TOOLS 15

3.8 PARTICIPANT INSTRUCTIONS 16

3.9 USABILITY METRICS 17

4 RESULTS 19

4.1 DATA ANALYSIS AND REPORTING 19

4.2 DISCUSSION OF THE FINDINGS 20

5 APPENDICES 22

5.1 APPENDIX 1: SAMPLE RECRUITING SCREENER 23

5.2 Appendix 2: PARTICIPANT DEMOGRAPHICS 26

5.3 Appendix 3: NON-DISCLOSURE AGREEMENT AND INFORMED CONSENT FORM 27

5.4 Appendix 4: EXAMPLE MODERATOR'S GUIDE 29

5.5 Appendix 5: SYSTEM USABILITY SCALE QUESTIONNAIRE 36

5.6 APPENDIX 6: INCENTIVE RECEIPT AND ACKNOWLEDGMENT FORM 36 


\section{EXECUTIVE SUMMARY}

A usability test of [name of product, version, and type of EHR] was conducted on [date] in [location] by [test laboratory]. The purpose of this test was to test and validate the usability of the current user interface, and provide evidence of usability in the EHR Under Test (EHRUT). During the usability test, $[X X]$ healthcare providers [and/or other intended users] matching the target demographic criteria served as participants and used the EHRUT in simulated, but representative tasks.

This study collected performance data on [Xx] tasks typically conducted on an EHR:

- Find information in Patient Summary screen

Use patient chart to find lab results

Check vital signs

[Continue with list]

During the [time, e.g., xx minute] one-on-one usability test, each participant was greeted by the administrator and asked to review and sign an informed consent/release form (included in Appendix 3); they were instructed that they could withdraw at any time. Participants [had/ did not have] prior experience with the EHR. ${ }^{4}$ The administrator introduced the test, and instructed participants to complete a series of tasks (given one at a time) using the EHRUT. During the testing, the administrator timed the test and, along with the data logger(s) recorded user performance data on paper and electronically. The administrator did not give the participant assistance in how to complete the task.

\footnotetext{
${ }^{4}$ If training or help materials were provided, describe the nature of it. The recommendation is that all participants be given the opportunity to complete training similar to what a real end user would receive prior to participating in the usability test.
} 
Participant screens, head shots and audio were recorded for subsequent analysis.

The following types of data were collected for each participant:

- Number of tasks successfully completed within the allotted time without assistance

- Time to complete the tasks

- Number and types of errors

- Path deviations

- Participant's verbalizations

- Participant's satisfaction ratings of the system

All participant data was de-identified - no correspondence could be made from the identity of the participant to the data collected. Following the conclusion of the testing, participants were asked to complete a post-test questionnaire and were compensated with [insert dollar amount or other incentive] for their time. Various recommended metrics, in accordance with the examples set forth in the NIST Guide to the Processes Approach for Improving the Usability of Electronic Health Records, were used to evaluate the usability of the EHRUT. Following is a summary of the performance and rating data collected on the EHRUT.

\begin{tabular}{|l|l|l|l|l|l|l|l|}
\hline \multirow{2}{*}{ Measure } & $\boldsymbol{N}$ & $\begin{array}{c}\text { Task } \\
\text { Suc- } \\
\text { cess }\end{array}$ & $\begin{array}{c}\text { Path } \\
\text { Deviation }\end{array}$ & \multicolumn{2}{|c|}{ Task Time } & Errors & $\begin{array}{c}\text { Task } \\
\text { Ratings } \\
\text { 5=Easy }\end{array}$ \\
\cline { 2 - 8 } & $\#$ & $\begin{array}{c}\text { Mean } \\
\text { (SD) }\end{array}$ & $\begin{array}{c}\text { Deviations } \\
\text { (Observed } \\
\text { / Optimal) }\end{array}$ & $\begin{array}{c}\text { Mean } \\
\text { (SD) }\end{array}$ & $\begin{array}{c}\text { Deviations } \\
\text { (Observed } \\
\text { / Optimal) }\end{array}$ & $\begin{array}{c}\text { Mean } \\
\text { (SD) }\end{array}$ & $\begin{array}{c}\text { Mean } \\
\text { (SD) }\end{array}$ \\
\hline $\begin{array}{c}\text { 1.[Find item on patient } \\
\text { summary screen] }\end{array}$ & & & & & & & \\
\hline $\begin{array}{c}\text { 2.[Use patient chart to } \\
\text { find lab results] }\end{array}$ & & & & & & & \\
\hline $\begin{array}{c}\text { 3.[Check vital signs] } \\
\text { Etc. }\end{array}$ & & & & & & & \\
\hline
\end{tabular}


The results from the System Usability Scale scored the subjective satisfaction with the system based on performance with these tasks to be: $[\mathrm{xx}]{ }^{1}$

In addition to the performance data, the following qualitative observations were made:

- Major findings

- [Details might include observations of user reactions to work flows, navigation, types of errors, screen designs, things that tested well, etc.]

- Areas for improvement

- [Provide details]

${ }^{1}$ See Tullis, T. \& Albert, W. (2008). Measuring the User Experience. Burlington, MA: Morgan Kaufman (p. 149). Broadly interpreted, scores under 60 represent systems with poor usability; scores over 80 would be considered above average. 


\section{INTRODUCTION}

The EHRUT(s) tested for this study was (were) [name of product, version and class]. Designed to present medical information to healthcare providers in [facility types and specialty setting], the EHRUT consists of [description of system and how it is used]. The usability testing attempted to represent realistic exercises and conditions.

The purpose of this study was to test and validate the usability of the current user interface, and provide evidence of usability in the EHR Under Test (EHRUT). . To this end, measures of effectiveness, efficiency and user satisfaction, such as [list some specific metrics (e.g., time on task)], were captured during the usability testing.

\section{METHOD}

\section{PARTICIPANTS}

A total of $[X X]$ participants were tested on the EHRUT(s). Participants in the test were [types of healthcare providers]. Participants were recruited by [name of recruiter/recruiting firm] and were compensated [insert dollar amount or other incentive (optional)] for their time. In addition, participants had no direct connection to the development of or organization producing the EHRUT(s). Participants were not from the testing or supplier organization. Participants were given the opportunity to have the same orientation and level of training as the actual end users would have received.

For the test purposes, end-user characteristics were identified and translated into a recruitment screener used to solicit potential participants; an example of a screener is provided in Appendix [1]. 
Recruited participants had a mix of backgrounds and demographic characteristics conforming to the recruitment screener. The following is a table of participants by characteristics, including demographics, professional experience, computing experience and user needs for assistive technology. Participant names were replaced with Participant IDs so that an individual's data cannot be tied back to individual identities.

\begin{tabular}{|l|c|l|l|l|l|l|l|l|l|}
\hline & $\begin{array}{c}\text { Part } \\
\text { ID }\end{array}$ & Gender & Age & Education & $\begin{array}{c}\text { Occupation/ } \\
\text { role }\end{array}$ & $\begin{array}{c}\text { Professional } \\
\text { Experience }\end{array}$ & $\begin{array}{c}\text { Computer } \\
\text { Experience }\end{array}$ & $\begin{array}{c}\text { Pssistive } \\
\text { Experience }\end{array}$ & $\begin{array}{c}\text { Technology } \\
\text { Needs }\end{array}$ \\
\hline $\mathbf{1}$ & & & & & & & & & \\
\hline $\mathbf{2}$ & & & & & & & & & \\
\hline$N$ & & & & & & & & & \\
\hline
\end{tabular}

[\#\#, i.e., total number of participants recruited] participants (matching the demographics in the section on Participants) were recruited and [\#\#, i.e., total number of participants who showed] participated in the usability test. [\#\#, i.e., number who failed to show] participants failed to show for the study.

Participants were scheduled for [time, e.g., xx minute] sessions with [time, e.g., $x x$ minutes] in between each session for debrief by the administrator(s) and data logger(s), and to reset systems to proper test conditions. A spreadsheet was used to keep track of the participant schedule, and included each participant's demographic characteristics as provided by the recruiting firm.

\section{STUDY DESIGN}

Overall, the objective of this test was to uncover areas where the application performed well - that is, effectively, efficiently, and with satisfaction - and areas where the application failed to meet the needs of 
the participants. The data from this test may serve as a baseline for future tests with an updated version of the same EHR and/or comparison with other EHRs provided the same tasks are used. In short, this testing serves as both a means to record or benchmark current usability, but also to identify areas where improvements must be made.

During the usability test, participants interacted with [number of] EHR(s). Each participant used the system in the same location, and was provided with the same instructions. The system was evaluated for effectiveness, efficiency and satisfaction as defined by measures collected and analyzed for each participant:

$\square$ Number of tasks successfully completed within the allotted time without assistance

$\square \quad$ Time to complete the tasks

$\square \quad$ Number and types of errors

$\square \quad$ Path deviations

口 Participant's verbalizations (comments)

$\square$ Participant's satisfaction ratings of the system

Additional information about the various measures can be found in Section 3.9 on Usability Metrics.

\section{TASKS}

A number of tasks were constructed that would be realistic and representative of the kinds of activities a user might do with this EHR, including:

1. Find patient's last visit date in patient summary screen

2. Find results of recent blood work

3. Check and record vital signs 4.

[add all tasks in short form] 
Tasks were selected based on their frequency of use, criticality of function, and those that may be most troublesome for users. ${ }^{6}$ Tasks should always be constructed in light of the study objectives.

\section{PROCEDURES}

Upon arrival, participants were greeted; their identity was verified and matched with a name on the participant schedule. Participants were then assigned a participant ID. ${ }^{7}$ Each participant reviewed and signed an informed consent and release form (See Appendix 3). A representative from the test team witnessed the participant's signature.

To ensure that the test ran smoothly, two staff members participated in this test, the usability administrator and the data logger. The usability testing staff conducting the test was experienced usability practitioners with [Number of years of experience, educational backgrounds, and qualifications of the test administrator(s) and data logger(s)].

The administrator moderated the session including administering instructions and tasks. The administrator also monitored task times, obtained post-task rating data, and took notes on participant comments. A second person served as the data logger and took notes on task success, path deviations, number and type of errors, and comments.

Participants were instructed to perform the tasks (see specific instructions below):

- As quickly as possible making as few errors and deviations as possible.

\footnotetext{
${ }^{6}$ Constructing appropriate tasks is of critical importance to the validity of a usability test. These are the actual functions, but most tasks contain larger and more fleshed out context that aligns with the sample data sets available in the tested EHR. Please consult usability references for guidance on how to construct appropriate tasks.

${ }^{7}$ All participant data must be de-identified and kept confidential.
} 
- Without assistance; administrators were allowed to give immaterial guidance and clarification on tasks, but not instructions on use.

- Without using a think aloud technique.

For each task, the participants were given a written copy of the task. Task timing began once the administrator finished reading the question. The task time was stopped once the participant indicated they had successfully completed the task. Scoring is discussed below in Section

\section{9.}

Following the session, the administrator gave the participant the post-test questionnaire (e.g., the System Usability Scale, see Appendix 5), compensated them for their time, and thanked each individual for their participation.

Participants' demographic information, task success rate, time on task, errors, deviations, verbal responses, and post-test questionnaire were recorded into a spreadsheet.

Participants were thanked for their time and compensated. Participants signed a receipt and acknowledgement form (See Appendix 6) indicating that they had received the compensation.

\section{TEST LOCATION}

The test facility included a waiting area and a quiet testing room with a table, computer for the participant, and recording computer for the administrator. Only the participant and administrator were in the test room. All observers and the data logger worked from a separate room where they could see the participant's screen and face shot, and listen to 
the audio of the session. To ensure that the environment was comfortable for users, noise levels were kept to a minimum with the ambient temperature within a normal range. All of the safety instruction and evacuation procedures were valid, in place, and visible to the participants.

\section{TEST ENVIRONMENT}

The EHRUT would be typically be used in a healthcare office or facility. In this instance, the testing was conducted in [describe facilities]. For testing, the computer used a [computer type] running [operating system]. The participants used [interaction style, e.g., a mouse and keyboard] when interacting with the EHRUT.

The [EHRUT] used [description of the display including screen size, resolution and color settings. If print-based, include the media size and print resolution.] The application was set up by the [vendor or test laboratory] according to the vendor's documentation describing the system set-up and preparation. The application itself was running on a [platform] using a [training / test database] on a [LAN / WAN] connection. Technically, the system performance (i.e., response time) was representative to what actual users would experience in a field implementation. Additionally, participants were instructed not to change any of the default system settings (such as control of font size).

\section{TEST FORMS AND TOOLS}

During the usability test, various documents and instruments were used, including:

1. Informed Consent

2. Moderator's Guide 


\section{Post-test Questionnaire}

4. Incentive Receipt and Acknowledgment Form

Examples of these documents can be found in Appendices 3-6

respectively. The Moderator's Guide was devised so as to be able to capture required data.

The participant's interaction with the EHRUT was captured and recorded digitally with screen capture software running on the test machine. A [video / web] camera recorded each participant's facial expressions synced with the screen capture, and verbal comments were recorded with a microphone. ${ }^{8}$ The test session were electronically transmitted to a nearby observation room where the data logger observed the test session.

\section{PARTICIPANT INSTRUCTIONS}

The administrator reads the following instructions aloud to the each participant (also see the full moderator's guide in Appendix [B4]):

Thank you for participating in this study. Your input is very important. Our session today will last about [XX minutes]. During that time you will use an instance of an electronic health record. I will ask you to complete a few tasks using this system and answer some questions. You should complete the tasks as quickly as possible making as few errors as possible. Please try to complete the tasks on your own following the instructions very closely. Please note that we are not testing you we are testing the system, therefore if you have difficulty all this means is that something needs to be improved in the system. I will be here in case you need specific help, but I am not able to instruct you or provide help in how to use the application.

Overall, we are interested in how easy (or how difficult) this system is to use, what in it would be useful to you, and how we could improve it. I did not have any involvement in its creation, so please be honest with your opinions. All of the information

\footnotetext{
${ }^{8}$ There are a variety of tools that record screens and transmit those recordings across a local area network for remote observations.
} 
that you provide will be kept confidential and your name will not be associated with your comments at any time. Should you feel it necessary you are able to withdraw at any time during the testing.

Following the procedural instructions, participants were shown the EHR and as their first task, were given time ([XX] minutes) to explore the system and make comments. Once this task was complete, the administrator gave the following instructions:

For each task, I will read the description to you and say "Begin." At that point, please perform the task and say "Done" once you believe you have successfully completed the task. I would like to request that you not talk aloud or verbalize while you are doing the tasks. ${ }^{9}$ I will ask you your impressions about the task once you are done.

Participants were then given $[X X]$ tasks to complete. Tasks are listed in the moderator's guide in Appendix [B4].

\section{USABILITY METRICS}

According to the NIST Guide to the Processes Approach for Improving the Usability of Electronic Health Records, EHRs should support a process that provides a high level of usability for all users. The goal is for users to interact with the system effectively, efficiently, and with an acceptable level of satisfaction. To this end, metrics for effectiveness, efficiency and user satisfaction were captured during the usability testing. The goals of the test were to assess:

1. Effectiveness of [EHRUT] by measuring participant success rates and errors

2. Efficiency of [EHRUT] by measuring the average task time and path deviations

\footnotetext{
${ }^{9}$ Participants should not use a think-aloud protocol during the testing. Excessive verbalization or attempts to converse with the moderator during task performance should be strongly discouraged. Participants will naturally provide commentary, but they should do so, ideally, after the testing. Some verbal commentary may be acceptable between tasks, but again should be minimized by the moderator.
} 
3. Satisfaction with [EHRUT] by measuring ease of use ratings

\section{DATA SCORING}

The following table (Table $[\mathrm{x}]$ ) details how tasks were scored, errors evaluated, and the time data analyzed. ${ }^{10}$

\begin{tabular}{|c|c|}
\hline Measures & Rationale and Scoring \\
\hline \multirow[t]{4}{*}{$\begin{array}{l}\text { Effectiveness: } \\
\text { Task Success }\end{array}$} & $\begin{array}{l}\text { A task was counted as a "Success" if the participant was able to } \\
\text { achieve the correct outcome, without assistance, within the time } \\
\text { allotted on a per task basis. }\end{array}$ \\
\hline & $\begin{array}{l}\text { The total number of successes were calculated for each task and then } \\
\text { divided by the total number of times that task was attempted. The } \\
\text { results are provided as a percentage. }\end{array}$ \\
\hline & $\begin{array}{l}\text { Task times were recorded for successes. Observed task times divided } \\
\text { by the optimal time for each task is a measure of optimal efficiency. }\end{array}$ \\
\hline & $\begin{array}{l}\text { Optimal task performance time, as benchmarked by expert } \\
\text { performance under realistic conditions, is recorded when constructing } \\
\text { tasks. Target task times used for task times in the Moderator's Guide } \\
\text { must be operationally defined by taking multiple measures of optimal } \\
\text { performance and multiplying by some factor [e.g., } 1.25] \text { that allows } \\
\text { some time buffer because the participants are presumably not trained } \\
\text { to expert performance. Thus, if expert, optimal performance on a task } \\
\left.\text { was [x] seconds then allotted task time performance was [x }{ }^{*} 1.25\right] \\
\text { seconds. This ratio should be aggregated across tasks and reported } \\
\text { with mean and variance scores. }\end{array}$ \\
\hline \multirow[t]{3}{*}{$\begin{array}{l}\text { Effectiveness: } \\
\text { Task Failures }\end{array}$} & $\begin{array}{l}\text { If the participant abandoned the task, did not reach the correct answer } \\
\text { or performed it incorrectly, or reached the end of the allotted time } \\
\text { before successful completion, the task was counted as an "Failures." } \\
\text { No task times were taken for errors. }\end{array}$ \\
\hline & $\begin{array}{l}\text { The total number of errors was calculated for each task and then } \\
\text { divided by the total number of times that task was attempted. Not all } \\
\text { deviations would be counted as errors. }{ }^{11} \text { This should also be } \\
\text { expressed as the mean number of failed tasks per participant. }\end{array}$ \\
\hline & $\begin{array}{l}\text { On a qualitative level, an enumeration of errors and error types should } \\
\text { be collected. }\end{array}$ \\
\hline $\begin{array}{l}\text { Efficiency: } \\
\text { Task Deviations }\end{array}$ & $\begin{array}{l}\text { The participant's path (i.e., steps) through the application was } \\
\text { recorded. Deviations occur if the participant, for example, went to a } \\
\text { wrong screen, clicked on an incorrect menu item, followed an incorrect } \\
\text { link, or interacted incorrectly with an on-screen control. This path was } \\
\text { compared to the optimal path. The number of steps in the observed } \\
\text { path is divided by the number of optimal steps to provide a ratio of path } \\
\text { deviation. }\end{array}$ \\
\hline
\end{tabular}

${ }^{10}$ An excellent resource is Tullis, T. \& Albert, W. (2008). Measuring the User Experience.

Burlington, MA: Morgan Kaufman. Also see www.measuringusability.com

${ }^{11}$ Errors have to be operationally defined by the test team prior to testing. 


\begin{tabular}{|l|l|}
\hline \multirow{2}{*}{ Efficiency: } & $\begin{array}{l}\text { It is strongly recommended that task deviations be reported. Optimal } \\
\text { paths (i.e., procedural steps) should be recorded when constructing } \\
\text { tasks. }\end{array}$ \\
\hline Satisfaction: & $\begin{array}{l}\text { Each task was timed from when the administrator said "Begin" until the } \\
\text { participant said, "Done." If he or she failed to say "Done," the time was } \\
\text { stopped when the participant stopped performing the task. Only task } \\
\text { times for tasks that were successfully completed were included in the } \\
\text { average task time analysis. Average time per task was calculated for } \\
\text { each task. Variance measures (standard deviation and standard error) } \\
\text { were also calculated. }\end{array}$ \\
$\begin{array}{l}\text { Participant's subjective impression of the ease of use of the } \\
\text { application was measured by administering both a simple post-task } \\
\text { question as well as a post-session questionnaire. After each task, the } \\
\text { participant was asked to rate "Overall, this task was:" on a scale of 1 } \\
\text { (Very Difficult) to 5 (Very Easy). These data are averaged across } \\
\text { participants. }\end{array}$ \\
$\begin{array}{l}\text { Common convention is that average ratings for systems judged easy } \\
\text { to use should be 3.3 or above. } \\
\text { To measure participants' confidence in and likeability of the [EHRUT] } \\
\text { overall, the testing team administered the System Usability Scale } \\
\text { (SUS) post-test questionnaire. Questions included, "I think I would } \\
\text { like to use this system frequently," "I thought the system was easy to } \\
\text { use," and "I would imagine that most people would learn to use this } \\
\text { system very quickly." See full System Usability Score questionnaire in } \\
\text { Appendix 5. }\end{array}$ \\
\hline
\end{tabular}

Table [x]. Details of how observed data were scored.

\section{RESULTS}

\section{DATA ANALYSIS AND REPORTING}

The results of the usability test were calculated according to the methods specified in the Usability Metrics section above. Participants who failed to follow session and task instructions had their data excluded from the analyses [Provide details if there are data exclusions.]. [Provide any

\footnotetext{
${ }^{12}$ See Tedesco and Tullis (2006) for a comparison of post-task ratings for usability tests. Tedesco, D. \& Tullis, T. (2006) A comparison of methods for eliciting post-task subjective ratings in usability testing. Usability Professionals association Conference, June $12-16$, Broomfield, $\mathrm{CO}$.

${ }^{13}$ The SUS survey yields a single number that represents a composite measure of the overall perceived usability of the system. SUS scores have a range of 0 to 100 and the score is a relative benchmark that is used against other iterations of the system.
} 
details of testing irregularities or issues that affected data collection or interpretation of the results.]

The usability testing results for the EHRUT are detailed below (see Table $[x])^{14}$.

The results should be seen in light of the objectives and goals outlined in Section 3.2 Study Design. The data should yield actionable results that, if corrected, yield material, positive impact on user performance. [Furthermore, the data should be presented in forms such as the table below so that the tasks can be easily identified and their performance results examined and compared.]

\begin{tabular}{|l|l|l|l|l|l|l|l|}
\hline & $N$ & $\begin{array}{c}\text { Task } \\
\text { Suc- } \\
\text { cess }\end{array}$ & $\begin{array}{c}\text { Path } \\
\text { Deviation }\end{array}$ & \multicolumn{2}{|c|}{ Task Time } & Errors & $\begin{array}{c}\text { Task } \\
\text { Ratings } \\
\text { 5=Easy }\end{array}$ \\
\cline { 2 - 8 } & $\#$ & $\begin{array}{c}\text { Mean } \\
\text { (SD) }\end{array}$ & $\begin{array}{c}\text { Deviations } \\
\text { (Observed } \\
\text { / Optimal) }\end{array}$ & $\begin{array}{c}\text { Mean } \\
\text { (SD) }\end{array}$ & $\begin{array}{c}\text { Deviations } \\
\text { (Observed } \\
\text { / Optimal) }\end{array}$ & $\begin{array}{c}\text { Mean } \\
\text { (SD) }\end{array}$ & $\begin{array}{c}\text { Mean } \\
\text { (SD) }\end{array}$ \\
\hline $\begin{array}{c}\text { 1.[Find item on patient } \\
\text { summary screen] }\end{array}$ & & & & & & & \\
\hline $\begin{array}{c}\text { 2.[Use patient chart to } \\
\text { find lab results] }\end{array}$ & & & & & & & \\
\hline $\begin{array}{l}\text { 3.[Check vital signs] } \\
\text { Etc. }\end{array}$ & & & & & & & \\
\hline
\end{tabular}

The results from the SUS (System Usability Scale) scored the subjective satisfaction with the system based on performance with these tasks to be:

[xx]. Broadly interpreted, scores under 60 represent systems with poor usability; scores over 80 would be considered above average. ${ }^{15}$

\section{DISCUSSION OF THE FINDINGS}

\footnotetext{
${ }^{14}$ Note that this table is an example. You will need to adapt it to report the actual data collected. ${ }^{15}$ See Tullis, T. \& Albert, W. (2008). Measuring the User Experience. Burlington, MA: Morgan Kaufman (p. 149).
} 
[The discussion should commence with a narrative discussion of each of the major areas in light of the findings]

\section{EFFECTIVENESS}

[Narrative of the effectiveness of the EHRUT in light of the findings. E.g., Based on the success, failure and path deviation data ...]

\section{EFFICIENCY}

[Narrative of the efficiency of the EHRUT in light of the findings. E.g., Based on the observations of the task time and deviation data ...]

\section{SATISFACTION}

[Narrative of the satisfaction data of the EHRUT in light of the findings.

E.g., Based on the task ratings and SUS results data ...]

\section{MAJOR FINDINGS}

[Narrative discussion of the interpretation of the quantitative findings, verbal report of the participants, and observations from the administrators and data loggers]

\section{AREAS FOR IMPROVEMENT}

[Narrative discussion of the interpretation of the quantitative findings, verbal report of the participants, and observations from the administrators and data loggers] 


\section{APPENDICES}

The following appendices include supplemental data for this usability test

report. Following is a list of the appendices provided:

1: Sample Recruiting screener

2: Participant demographics

3: Non-Disclosure Agreement (NDA) and Informed Consent

Form

4: Example Moderator's Guide

5: System Usability Scale Questionnaire

6: Incentive receipt and acknowledgment form

It is important to note that these Appendices are examples only. They are not intended to be used exactly as rendered below.

For example, the intended users of the system will determine sampling requirements which drive screener questions. Likewise, the goals of the study will determine the exact tasks and data to be recorded; this will create the tasks and data collection plan in the moderator's guide.

See some of the previously cited references for examples of these documents. 


\section{Appendix 1: SAMPLE RECRUITING SCREENER}

The purpose of a screener to ensure that the participants selected represent the target user population as closely as possible. (Portions of this sample screener are taken from www.usability.gov/templates/index.htm|\#Usability and adapted for use.)

\section{Recruiting Script for Recruiting Firm}

Hello, my name is , calling from [Insert name of recruiting firm]. We

are recruiting individuals to participate in a usability study for an electronic health record.

We would like to ask you a few questions to see if you qualify and if would like to participate. This should only take a few minutes of your time. This is strictly for research purposes. If you are interested and qualify for the study, you will be paid to participate.

Can I ask you a few questions?

Customize this by dropping or adding questions so that it reflects your EHR's primary audience

1. [If not obvious] Are you male or female? [Recruit a mix of participants]

2. Have you participated in a focus group or usability test in the past $x x$ months? [If yes, Terminate]

3. Do you, or does anyone in your home, work in marketing research, usability research, web design [...etc.]? [If yes, Terminate]

4. Do you, or does anyone in your home, have a commercial or research interest in an electronic health record software or consulting company? [If yes, Terminate]

5. Which of the following best describes your age? [23 to 39; 40 to $59 ; 60$ - to $74 ; 75$ and older] [Recruit Mix]

6. Which of the following best describes your race or ethnic group? [e.g., Caucasian, Asian, Black/African-American, Latino/a or Hispanic, etc.]

7. Do you require any assistive technologies to use a computer? [if so, please describe]

Professional Demographics Customize this to reflect your EHR's primary audience

8. What is your current position and title? (Must be healthcare provider)

$\mathrm{RN}$ : Specialty

Physician: Specialty

Resident: Specialty

Administrative Staff

Other [Terminate] 
9. How long have you held this position?

10. Describe your work location (or affiliation) and environment? (Recruit according to the intended users of the application) [e.g., private practice, health system, government clinic, etc.]

11. Which of the following describes your highest level of education? [e.g., high school graduate/GED, some college, college graduate (RN, BSN), postgraduate (MD/PhD), other (explain)]

Computer Expertise Customize this to reflect what you know about your EHR's audience

12. Besides reading email, what professional activities do you do on the computer? [e.g., access EHR, research; reading news; shopping/banking; digital pictures; programming/word processing, etc.] [If no computer use at all, Terminate]

13. About how many hours per week do you spend on the computer? [Recruit according to the demographics of the intended users, e.g., 0 to 10,11 to $25,26+$ hours per week]

14. What computer platform do you usually use? [e.g., Mac, Windows, etc.]

15. What Internet browser(s) do you usually use? [e.g., Firefox, IE, AOL, etc.]

16. In the last month, how often have you used an electronic health record?

17. How many years have you used an electronic health record?

18. How many EHRs do you use or are you familiar with?

19. How does your work environment patient records? [Recruit according to the demographics of the intended users]

$\square$ On paper

Some paper, some electronic

All electronic

Contact Information If the person matches your qualifications, ask

Those are all the questions I have for you. Your background matches the people we're looking for. [If you are paying participants or offering some form of compensation, mention] For your participation, you will be paid [amount].

Would you be able to participate on [date, time]? [If so collect contact information]

\section{May I get your contact information?}

- Name of participant:

- Address:

- City, State, Zip:

- Daytime phone number:

- Evening phone number:

- Alternate [cell] phone number:

- Email address: 
Before your session starts, we will ask you to sign a release form allowing us to videotape your session. The videotape will only be used internally for further study if needed. Will you consent to be videotaped?

This study will take place at [location]. I will confirm your appointment a couple of days before your session and provide you with directions to our office. What time is the best time to reach you? 


\section{Appendix 2: PARTICIPANT DEMOGRAPHICS}

The report should contain a breakdown of the key participant demographics. A representative list is shown below.

Following is a high-level overview of the participants in this study.

\begin{tabular}{ll} 
Gender & \\
\hline Men & {$[\mathrm{X}]$} \\
Women & {$[\mathrm{X}]$} \\
Total (participants) & {$[\mathrm{X}]$}
\end{tabular}

Occupation/Role

\begin{tabular}{ll}
\hline RN/BSN & {$[X]$} \\
Physician & {$[X]$} \\
Admin Staff & {$[X]$} \\
Total (participants) & {$[X]$}
\end{tabular}

Years of Experience

$\begin{array}{lr}\text { Years experience } & {[\mathrm{X}]} \\ \begin{array}{l}\text { Facility Use of EHR } \\ \text { All paper }\end{array} & {[\mathrm{X}]} \\ \begin{array}{l}\text { Some paper, some } \\ \text { electronic }\end{array} & {[\mathrm{X}]} \\ \begin{array}{l}\text { All electronic } \\ \text { Total (participants) }\end{array} & {[\mathrm{X}]} \\ & {[\mathrm{X}]}\end{array}$

As an appendix to the report, the full participant breakdown (de-identified) should be included. 


\section{Appendix 3: NON-DISCLOSURE AGREEMENT AND INFORMED CONSENT FORM}

These are sample forms. The non-disclosure agreement is discretionary. Other examples may be found at www. usability.gov.

\section{Non-Disclosure Agreement}

THIS AGREEMENT is entered into as of 2010, between ("the Participant") and the testing organization Test Company

located at Address.

The Participant acknowledges his or her voluntary participation in today's usability study may bring the Participant into possession of Confidential Information. The term "Confidential Information" means all technical and commercial information of a proprietary or confidential nature which is disclosed by Test Company, or otherwise acquired by the Participant, in the course of today's study.

By way of illustration, but not limitation, Confidential Information includes trade secrets, processes, formulae, data, know-how, products, designs, drawings, computer aided design files and other computer files, computer software, ideas, improvements, inventions, training methods and materials, marketing techniques, plans, strategies, budgets, financial information, or forecasts.

Any information the Participant acquires relating to this product during this study is confidential and proprietary to Test Company and is being disclosed solely for the purposes of the Participant's participation in today's usability study. By signing this form the Participant acknowledges that s/he will receive monetary compensation for feedback and will not disclose this confidential information obtained today to anyone else or any other organizations.

\section{Participant's printed name:}

Signature:

Date: 


\section{Informed Consent}

Test Company would like to thank you for participating in this study. The purpose of this study is to evaluate an electronic health records system. If you decide to participate, you will be asked to perform several tasks using the prototype and give your feedback. The study will last about 60 minutes. At the conclusion of the test, you will be compensated for your time.

Agreement

I understand and agree that as a voluntary participant in the present study conducted by Test Company I am free to withdraw consent or discontinue participation at any time. I understand and agree to participate in the study conducted and videotaped by the Test Company.

I understand and consent to the use and release of the videotape by Test Company. I understand that the information and videotape is for research purposes only and that my name and image will not be used for any purpose other than research. I relinquish any rights to the videotape and understand the videotape may be copied and used by Test Company without further permission.

I understand and agree that the purpose of this study is to make software applications more useful and usable in the future.

I understand and agree that the data collected from this study may be shared with outside of Test Company and Test Company's client. I understand and agree that data confidentiality is assured, because only deidentified data - i.e., identification numbers not names - will be used in analysis and reporting of the results.

I agree to immediately raise any concerns or areas of discomfort with the study administrator. I understand that I can leave at any time.

Please check one of the following:

YES, I have read the above statement and agree to be a participant.

NO, I choose not to participate in this study. 
Appendix 4: EXAMPLE MODERATOR'S GUIDE

Only three tasks are presented here for illustration.

\section{EHRUT Usability Test}

Moderator's Guide

\section{Administrator}

Data Logger

Date Time

\section{Participant \#}

\section{Location}

Prior to testing

- Confirm schedule with Participants

- Ensure EHRUT lab environment is running properly

- Ensure lab and data recording equipment is running properly

Prior to each participant:

- Reset application

- Start session recordings with tool

Prior to each task:

- Reset application to starting point for next task

After each participant:

- End session recordings with tool

After all testing

- Back up all video and data files 


\section{Orientation ( $X$ minutes)}

Thank you for participating in this study. Our session today will last $\boldsymbol{X} \boldsymbol{X}$ minutes. During that time you will take a look at an electronic health record system.

I will ask you to complete a few tasks using this system and answer some questions. We are interested in how easy (or how difficult) this system is to use, what in it would be useful to you, and how we could improve it. You will be asked to complete these tasks on your own trying to do them as quickly as possible with the fewest possible errors or deviations. Do not do anything more than asked. If you get lost or have difficulty I cannot answer help you with anything to do with the system itself. Please save your detailed comments until the end of a task or the end of the session as a whole when we can discuss freely.

I did not have any involvement in its creation, so please be honest with your opinions.

The product you will be using today is describe the state of the application, i.e., production version, early prototype, etc. Some of the data may not make sense as it is placeholder data.

We are recording the audio and screenshots of our session today. All of the information that you provide will be kept confidential and your name will not be associated with your comments at any time.

Do you have any questions or concerns?

\section{Preliminary Questions ( $X$ minutes)}

What is your job title / appointment?

How long have you been working in this role?

What are some of your main responsibilities?

Tell me about your experience with electronic health records. 
Task 1: First Impressions ( $X X X$ Seconds)

This is the application you will be working with. Have you heard of it?

Yes No

If so, tell me what you know about it.

- Show test participant the EHRUT.

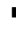

- Please don't click on anything just yet. What do you notice? What are you able to do here? Please be specific.

Notes / Comments: 
Task 2: Patient Summary Screen (XXX Seconds)

Take the participant to the starting point for the task.

Before going into the exam room and you want to review Patient's chief complaint, history, and vitals. Find this information.

Success:

$\square$ Easily completed

Completed with difficulty or help :: Describe below

Not completed

Comments:

Task Time: Seconds

Optimal Path: Screen A $\rightarrow$ Screen B $\rightarrow$ Drop Down $B^{l} \rightarrow$ "OK” Button $\rightarrow$ Screen X...

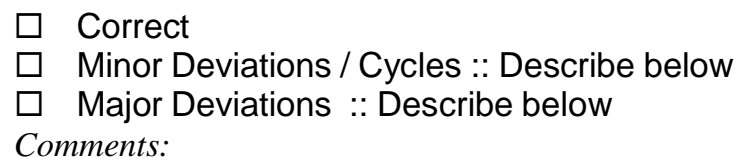

Observed Errors and Verbalizations:

Comments:

Rating:

Overall, this task was:

Show participant written scale: "Very Difficult" (1) to "Very Easy" (5)

Administrator / Notetaker Comments: 
Task 3: Find Lab Results ( $X X X$ Seconds)

Take the participant to the starting point for the task.

On her last visit, you sent Patient to get a colonscopy. Locate these results and review the notes from the specialist.

Success:

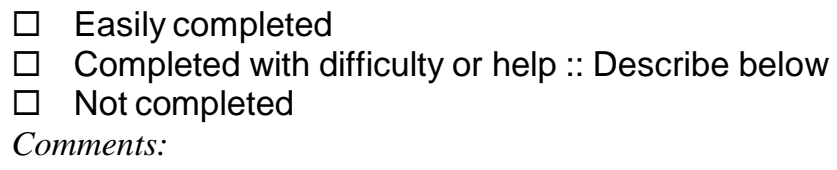

Task Time: Seconds

Optimal Path: Screen A $\rightarrow$ Screen B $\rightarrow$ Drop Down $B^{l} \rightarrow$ “OK” Button $\rightarrow$ Screen X...

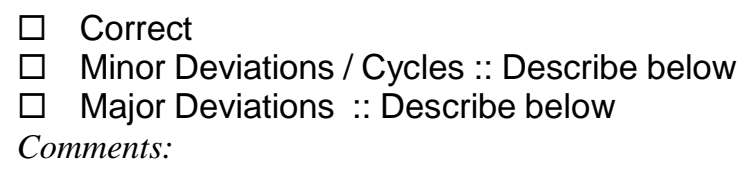

Observed Errors and Verbalizations:

Comments:

Rating:

Overall, this task was:

Show participant written scale: "Very Difficult" (1) to "Very Easy" (5)

\section{Administrator / Notetaker Comments:}


Task 4: Prescribe medication $(X X X$ Seconds)

Take the participant to the starting point for the task. Ensure that this patient has a drug-drug and a drug-food allergy to the drug chosen. This will put force the participant to find other drugs and use other elements of the application.

After examining Patient, you have decided to put this patient on a statin - drug name. Check for any interactions and place an order for this medication.

Success:

Easily completed

Completed with difficulty or help :: Describe below

Not completed

Comments:

Task Time: Seconds

Optimal Path: Screen A $\rightarrow$ Screen B $\rightarrow$ Drop Down $B^{l} \rightarrow$ "OK” Button $\rightarrow$ Screen X...

$\square$ Correct

$\square$ Minor Deviations / Cycles :: Describe below

Major Deviations :: Describe below

Comments:

Observed Errors and Verbalizations:

Comments:

Rating:

Overall, this task was:

Show participant written scale: "Very Difficult" (1) to "Very Easy" (5)

\section{Administrator / Notetaker Comments:}




\section{Final Questions (X Minutes)}

What was your overall impression of this system?

What aspects of the system did you like most?

What aspects of the system did you like least?

Were there any features that you were surprised to see?

What features did you expect to encounter but did not see? That is, is there anything that is missing in this application?

Compare this system to other systems you have used.

Would you recommend this system to your colleagues?

Administer the SUS 


\section{Appendix 5: SYSTEM USABILITY SCALE QUESTIONNAIRE}

In 1996, Brooke published a "low-cost usability scale that can be used for global assessments of systems usability" known as the System Usability Scale or SUS. ${ }^{16}$ Lewis and Sauro (2009) and others have elaborated on the SUS over the years. Computation of the SUS score can be found in Brooke's paper, in at http://www.usabilitynet.org/trump/documents/Suschapt.doc or in Tullis and Albert (2008).
Strongly
Strongly
disagree
agree

1. I think that I would like to use this system frequently

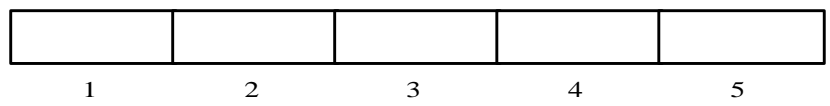

2.I found the system unnecessarily complex

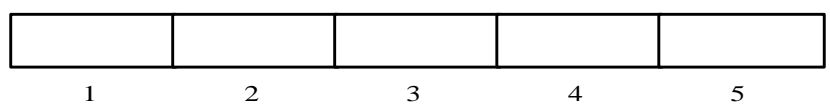

3.I thought the system was easy to use

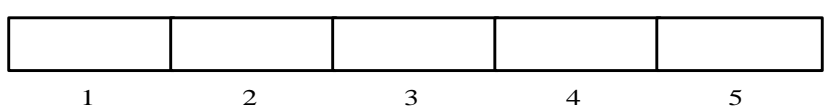

4.I think that I would need the support of a technical person to be able to use this system

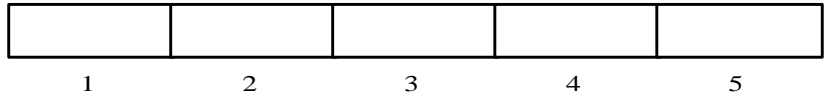

5.I found the various functions in this system were well integrated

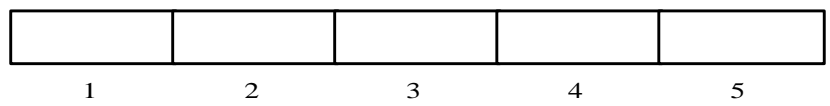

6.I thought there was too much inconsistency in this system

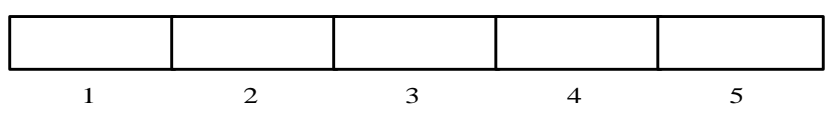

7.I would imagine that most people would learn to use this system very quickly

8.I found the system very cumbersome to use
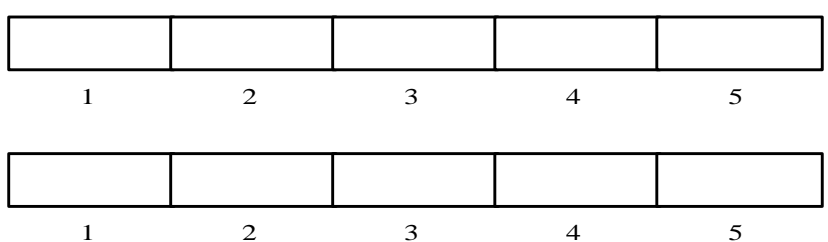

9.I felt very confident using the system

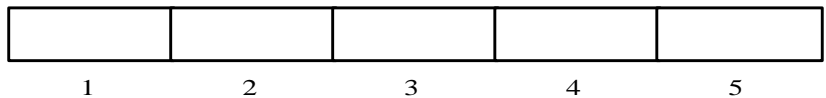

10. I needed to learn a lot of things before I could get going with this system

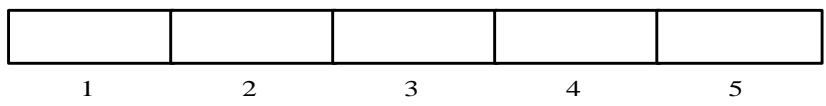

\footnotetext{
${ }^{16}$ Brooke, J.: SUS: A “quick and dirty” usability scale. In: Jordan, P. W., Thomas, B., Weerdmeester, B. A., McClelland (eds.) Usability Evaluation in Industry pp. 189--194. Taylor \& Francis, London, UK (1996). SUS is copyrighted to Digital Equipment Corporation, 1986.

Lewis, J R \& Sauro, J. (2009) "The Factor Structure Of The System Usability Scale." in Proceedings of the Human Computer Interaction International Conference (HCII 2009), San Diego CA, USA
} 
Appendix 6: INCENTIVE RECEIPT AND ACKNOWLEDGMENT FORM

\section{Acknowledgement of Receipt}

I hereby acknowledge receipt of $\$ \_$for my participation in a research study run by Test Company.

Printed Name:

Address:

Signature: Date:

Usability Researcher:

Signature of Usability Researcher:

Date:

Witness:

Witness Signature:

Date: 